\title{
Evaluation of a home based health record booklet
}

\author{
A D LAKHANI, A AVERY, A GORDON, AND N TAIT \\ Department of Community Medicine, St Thomas's Hospital Medical School, London
}

SUMMARY Despite the widespread use of home based child health records of varying complexity in England, there is a notable absence of their evaluation. Such a record booklet developed in the West Lambeth Health Authority has been used by parents, doctors, and community nurses to build up an independent chronological record of a child's birth statistics, health, growth, immunisation, development checks, and contacts with health services. A randomised controlled evaluation of the record, analyses of entries in it, and a survey of the views of mothers and health professionals using the record have been carried out. The need for such a record was confirmed by those questioned and analyses of entries in the booklet helped to modify and improve it. The evaluation was unable to show, however, any effect of the record on immunisation and developmental assessment service uptake. Its value in improving communication between the numerous health and other care agencies was dependent on its proper use.

Home based child health records are widely used, particularly in countries that do not have centralised health service records. ${ }^{1}$ The records vary in complexity from the simple 'Road to Health' card ${ }^{2}$ developed by the World Health Organisation to the comprehensive French 'Carnet de Sante'. ${ }^{34}$ In England, general practitioners, child health clinics, and hospitals have their own record storage and retrieval facilities and the role of these home based records is at present limited. Communication, however, between the numerous health agencies caring for children is often poor. At present home based records of varying complexity are widely used in England, an example being the 'Child Health Record' developed by the Society of Area Nurses (Child Health). ${ }^{5}$

A multidisciplinary group set up in 1977 in the West Lambeth Health District considered the introduction of such a booklet. A small, simple, health record booklet kept at home by parents, with a chronological record of every illness and contact the child had with any of the numerous child health care agencies, that is general practitioner, health visitor, community health doctor, paediatrician, casualty doctor, district nurse, social worker, and school nurse was recommended. The group made a recommendation not to include health education information within the booklet but to make this available as an accompanying booklet of the same size and with a similar cover design, as the advice was likely to change over the potential 10 to 15 year lifetime of the record booklet and could prejudice its use. The accompanying health education booklet could be updated periodically without interfering with the chronological health record. It was considered that existing booklets did not meet these criteria and a local booklet was developed.

It was assumed that losses of an attractive booklet would be minimal, hence a gold cover was designed. An inside front cover flap had simple instructions on how to use the booklet. The flap pocket contained two change of address postcards, stamped and addressed to the community health department, a feature quite important with a mobile inner city population. The booklet contained spaces for a photograph; name; birth statistics; four address changes; important names and telephone numbers, for example general practitioner, health visitor, family planning clinic, child health clinic, dentist, nearest casualty department; developmental milestones; and a schedule and record of immunisation and developmental assessment clinic attendance. Two single sex weight charts, from 0 to 2 years and 2 to 10 years were included. Several record pages contained spaces for a chronological record of all illnesses and contact the child had with any health agency. Where the health professionals were unable to, parents were encouraged to enter information themselves and maintain a complete chronological record of the date, age, weight, place of contact, reason for visit, recommendations, signature, and designation of the health professional. 
In the absence of evaluations of other such records it was decided to evaluate this one in terms of its efficiency and its effectiveness. The measures to be used included immunisation uptake, developmental assessment clinic attendance, analyses of entries in the booklet, and the views of parents and health professionals on the booklet.

\section{Method}

It was assumed that the booklet would improve the uptake of immunisation services in the health district and this hypothesis was to be tested using a randomised controlled trial, with one group of mothers selected at random given the booklet (the study group) and another group of mothers selected at random not given the booklet but followed up (the control group). The uptake of immunisation and development assessment services by both groups was to be monitored and compared. A sample size of 225 in each of a study and control group was calculated, assuming immunisation uptake of $70 \%$ at the start and increasing by $12 \%$ over the study period, allowing for the birth rate and administrative constraints. The efficiency of the use of the booklet was to be studied by collecting booklets after a year of use and analysing their recorded contents. The views of parents and health professionals on the booklet were to be studied through interviews and postal questionnaires.

After informing all child health professionals of the project, mothers resident in the West Lambeth Health District and discharged from obstetric wards at St Thomas's hospital between May and August 1980 were identified. A balanced random plan was produced, allocating postnatal wards at the hospital into study and control wards for each week of the study period, so that each ward was a study ward for half the weeks during the four months. All the identified mothers on the study wards formed the study group and the mothers on the control wards formed the control group. The matching of the resultant study and control groups was checked. Personal data on each mother were collected on the ward using a structured interview. At discharge, mothers on study wards were given a booklet in a sealed envelope and asked to discuss its use with health visitors.

Data were collected on address changes, immunisation uptake, and developmental assessment clinic attendance within 12 months of birth, from clinic, health visitor, and some general practitioner records for each child. At the end of one year mothers in the study and control groups remaining in the district were interviewed at home. The booklet was being widely distributed by then, and control mothers had to be interviewed to determine how many had acquired booklets and to compare their knowledge of local services with that of study mothers, thus evaluating the information section. Using a structured questionnaire, all mothers were asked about their knowledge of local services and the study mothers were then asked questions about their views on the booklet and each section. Those booklets that were available were then photocopied for a detailed analysis of entries in individual sections, using a validated coding form.

It had been decided that booklets would be distributed to all mothers in the district with babies born after 1 September 1980 , that is after the study and control groups had been identified. The views of the health professionals on the value of the booklet were dependent on widespread experience of the use of the booklet. In the autumn of 1981 postal questionnaires, previously piloted, were completed by health visitors, community health doctors, and general practitioners in the district. Non-responders were sent one reminder. Informal small group discussions were also held with health visitors to discuss issues not identified in the structured questionnaire.

\section{Results}

Analysis of the personal data showed that the study and control groups were well matched by age, parity, education, first language, mothers' place of birth, social class, race, religion, place of antenatal care, type of delivery, baby's birthweight, and type of feeding on the ward. There were, however, more single mothers and female babies in the study group than in the control group.

Table 1 shows the study and control group sizes and the revised groups at the end of one year. The

Table 1 Study and control group numbers

\begin{tabular}{|c|c|c|c|}
\hline & Study & Control & Total \\
\hline Number at start & 242 & 237 & 479 \\
\hline $\begin{array}{l}\text { Missing data (eg no date of } \\
\text { birth, final address etc) }\end{array}$ & $2^{*}$ & $7^{*}$ & $9^{*}$ \\
\hline Left health district & $56^{*}$ & $61^{*}$ & $117^{*}$ \\
\hline Died or taken into care & $4^{*}$ & $1^{*}$ & $5^{*}$ \\
\hline $\begin{array}{l}\text { Remaining in district and } \\
\text { eligible for interview }\end{array}$ & $180(178)$ & $168(165)$ & $348(343)$ \\
\hline Non-response to interview & $(10)^{*}$ & $(11)^{*}$ & $(21)^{*}$ \\
\hline Interviewed & $170(168)$ & $157(154)$ & $327(322)$ \\
\hline Claimed to own book & (157) & $(12)^{*}$ & (169) \\
\hline $\begin{array}{l}\text { Revised study/control groups for } \\
\text { comparison of service uptake } \\
\text { (one baby in every set of twins } \\
\text { included) }\end{array}$ & $157(157)$ & $142(142)$ & 299 (299) \\
\hline
\end{tabular}

*Excluded.

The figures are numbers of babies, except for figures in brackets which are numbers of mothers, the difference being due to twins. 
two groups were still well matched after the revision. During the year, $24.4 \%$, (117) of the babies had left the district, nine babies could not be traced, one baby was in care, and four babies had died. There were, therefore, 348 babies remaining in the district, but only 343 mothers due to five sets of twins. Of the 343 mothers eligible for interview, 322 were interviewed, a response rate of $93.9 \%$. Eleven of the 168 study mothers interviewed claimed they had never received a booklet and 12 of the control mothers said they had received one, possibly due to errors in the initial distribution of booklets by ward staff. One hunded and forty four of the 157 study mothers and 12 control mothers with booklets were able to produce the booklet at an unheralded interview, 24 mothers claimed to have the booklet but could not find it at the time, and only one mother admitted to losing it. Four mothers refused to give up their booklets and thus 140 booklets were collected, photocopied for analysis, and returned to the mothers. Table 2 shows the proportion of the 140 booklets that had entries in the various sections.

Thirty eight $(97 \%)$ of the 39 health visitors, 15 $(67 \%)$ of the 21 clinical medical officers, and 55 $(60 \%)$ of the 92 general practitioners responded to the questionnaire.

The whole booklet. At interview it was observed that $86 \%$ of the 144 booklets were kept in a safe place and most were in good condition. Ninety seven per cent of the 169 mothers who had received a booklet said they liked it, $85 \%$ said they always took it to the clinic, $70 \%$ said they had made entries in it themselves, and $92 \%$ thought its size was adequate. Only 16 out of 106 mothers who had seen other local or commercial booklets said they preferred those to this one.

All 38 health visitors, all 15 clinical medical officers, and 49 of the 55 general practitioners who responded thought that parents should keep an independent record of their child's health and development, and most of these professionals felt that the aim of the booklet as a complete record of the child's health and progress was well achieved (Table 3). Ninety two per cent (35) of the health visitors and all 15 clinical medical officers said they would recommend this booklet to other professionals. Several health visitors claimed that the booklet was a useful tool in establishing a rapport with mothers and $78 \%$ (30) said they usually distributed the booklet to mothers on their first visit. All 37 health visitors and all 11 clinical medical officers who knew other booklets said they preferred this one.

Cover, instructions, front page. The cover design
Table 2 Book entries by section

\begin{tabular}{|c|c|c|}
\hline Section & Item & $\begin{array}{l}\% \text { of } 140 \text { booklets } \\
\text { with entries }\end{array}$ \\
\hline \multicolumn{3}{|l|}{$\begin{array}{l}\text { Name and birth } \\
\text { information }\end{array}$} \\
\hline & Photograph & 10 \\
\hline & Surname & 100 \\
\hline & First name & 99 \\
\hline & Date of birth & 99 \\
\hline & Time of birth & 85 \\
\hline & Birthweight & 96 \\
\hline & Hospital & 99 \\
\hline & Gestation & 79 \\
\hline & Delivery & 84 \\
\hline Address & & 93 \\
\hline Weight chart & & 74 \\
\hline \multirow[t]{2}{*}{ Record pages } & Records & 99 \\
\hline & Allergies & 2 \\
\hline \multicolumn{3}{|l|}{$\begin{array}{l}\text { Important names and } \\
\text { telephone numbers }\end{array}$} \\
\hline & General practitioner & 49 \\
\hline & Health visitor & 62 \\
\hline & Family planning clinic & 39 \\
\hline & Dentist & 9 \\
\hline & Nearest hospital & 31 \\
\hline & Social services & 36 \\
\hline & Nearest casualty department & 36 \\
\hline Notes page & & 18 \\
\hline \multicolumn{3}{|l|}{ Milestones } \\
\hline & Smiled (P) & 50 \\
\hline & Sat $(P)$ & 32 \\
\hline & Walked (P) & 2 \\
\hline & One Word $(P)$ & 4 \\
\hline & Teeth (B) & 13 \\
\hline & Other (B) & 11 \\
\hline \multicolumn{3}{|c|}{$\begin{array}{l}\text { Immunisation and } \\
\text { developmental assessment } \\
\text { Appointments } \\
\text { made and recorded }\end{array}$} \\
\hline & First assessment & 46 \\
\hline & First immunisation & 20 \\
\hline & Second immunisation & 17 \\
\hline & Second assessment & 16 \\
\hline & Third immunisation & 12 \\
\hline \multirow[t]{5}{*}{ Uptake recorded } & First assessment & 19 \\
\hline & First immunisation & 51 \\
\hline & Second immunisation & 36 \\
\hline & Second assessment & 14 \\
\hline & Third immunisation & 1 \\
\hline
\end{tabular}

(P) provided.

(B) blank space filled.

was based on a preference expressed at the pilot stage by parents and health professionals. At interview, $72 \%$ of the mothers said they were satisfied with the cover. Change of address cards were received by the community health offices for $14 \%$ of the known moves in the study group but some cards might have been received and the researchers not notified. The community offices have confirmed that cards are being received regularly. Only $10 \%$ of the booklets had a photograph in them, but the rest of the front page was well used (Table 2).

Weight charts. The number of points plotted per weight chart ranged from 0 to 17 with a mean of $5 \cdot 8$, 
Table 3 Responses of professionals to questions on the value of the booklet

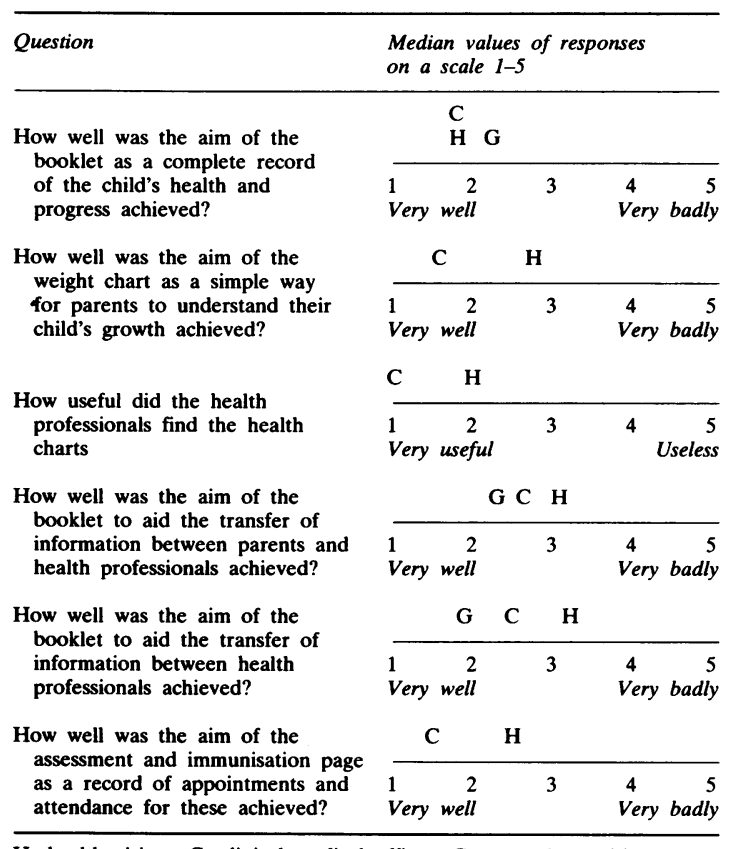

$\mathbf{H}=$ health visitor, $\mathbf{C}=$ clinical medical officer, $\mathbf{G}=$ general practitioner.

and $74 \%$ of the charts had at least one point. The points, when checked for accuracy of plotting to within two weeks and one pound of recorded weights, showed that $64 \%$ of birthweights were accurately plotted but only $40 \%$ of the final weights were accurately plotted. The overall accuracy was about $52 \%$. It was interesting to note that $44 \%(74)$ of the mothers said they would like to fill in the weight charts themselves, $11 \%$ (18) claimed that they had filled them in themselves, and $43 \%$ (73) showed at interview that they understood them. Clinical medical officers and health visitors claimed to find the charts useful and thought they did help parents to understand their child's weight (Table 3).

Record pages. The number of entries made per booklet in the health contact record section ranged from 0 to 28 , with a mean of 10.9 , and 139 of the 140 booklets had at least one entry. Of the 1543 entries analysed, $38.5 \%$ were made by health visitors, $25.5 \%$ were records of clinical attendance for weighing only, $8.5 \%$ were made by clinical medical officers, $7 \cdot 0 \%$ by parents, $3.0 \%$ by general practitioners, $1.5 \%$ by hospital doctors, and the rest were either unsigned or not legible. The health professionals thought that the aim of the record pages as an aid for the transfer of information among health workers and between health workers and parents was well achieved, though health visitors thought this was less so than general practitioners and clinical medical officers (Table 3 ).

Development page. This page was to be the parent's own record. Some early milestones were given but the rest of the page was left blank. This page was not used as well as had been anticipated (Table 2). Fifty one per cent of the booklets had at least one entry. The most commonly quoted milestone which was not among those given was the appearance of teeth.

Information. Up to $50 \%$ of the booklets had entries on this page (Table 2). At interview, responses of the mothers to their knowledge of local services were coded as certain, vague, or not known. There was no significant difference in knowledge between the study and control mothers. Only a small proportion of study mothers who were uncertain said they would refer to the booklet.

Immunisation and development assessment. Health visitors and clinical medical officers thought that the aim of this page as a record of immunisation and assessment appointments and uptake was well achieved (Table 3). The proportion of booklets with entries on this page was low, however, (Table 2) and information was still being recorded on an immunisation card that had been used previously. In fact, $52 \%$ of the booklets contained this card inside the front cover flap. There was no significant difference in the uptake of immunisation and developmental assessment clinic attendance between the study and control groups (Table 4).

Table 4 Uptake of immunisation and developmental assessment clinic attendance by group (\%)

\begin{tabular}{|c|c|c|c|}
\hline & $\begin{array}{l}\text { Study } \\
\text { group }\end{array}$ & $\begin{array}{l}\text { Control } \\
\text { group }\end{array}$ & Total \\
\hline No in Group (Table 1) & 157 & 142 & 299 \\
\hline $\begin{array}{l}\text { Diphtheria/tetanus/polio (DTP) } \\
\text { 1st dose }\end{array}$ & 90 & 94 & 92 \\
\hline $\begin{array}{l}\text { Diphtheria/tetanus/polio } \\
\text { 2nd dose }\end{array}$ & 76 & 85 & 80 \\
\hline $\begin{array}{l}\text { Diphtheria/tetanus/polio } \\
\text { 3rd dose }\end{array}$ & 22 & 31 & 26 \\
\hline Pertussis-1st dose & 64 & 58 & 62 \\
\hline Pertussis -2 nd dose & 58 & 59 & 59 \\
\hline Pertussis-3rd dose & 19 & 19 & 19 \\
\hline 1st development assessment & 96 & 98 & 97 \\
\hline 2nd development assessment & 78 & 84 & 80 \\
\hline \multirow{2}{*}{\multicolumn{4}{|c|}{ Of the 348 babies remaining in the district }} \\
\hline & DTP & 1 & $(0 \cdot 3)$ \\
\hline No $(\%)$ & Pertussis & 27 & $(7 \cdot 7)$ \\
\hline No consent for immunisation & DTP & 5 & $(1.4)$ \\
\hline No $(\%)$ & Pertussis & 71 & $(20 \cdot 4)$ \\
\hline
\end{tabular}


Table 5 Social factors in the use of the record booklet

\begin{tabular}{|c|c|c|c|c|c|c|}
\hline \multirow[t]{3}{*}{ Variable } & \multicolumn{6}{|c|}{ Number of entries } \\
\hline & \multicolumn{2}{|c|}{ Weight charts* } & \multicolumn{2}{|c|}{ Record pages } & \multicolumn{2}{|c|}{$\begin{array}{l}\text { Development } \\
\text { milestones }\end{array}$} \\
\hline & Not & Median & No & Median & No & Median \\
\hline \multicolumn{7}{|c|}{ Mother's first language } \\
\hline English & 111 & $3 \cdot 0$ & 113 & $9 \cdot 0$ & 113 & $1 \cdot 0$ \\
\hline Non-English & 26 & $2 \cdot 5$ & 27 & $10 \cdot 0$ & 27 & $0 \cdot 0 \ddagger$ \\
\hline \multicolumn{7}{|c|}{$\begin{array}{l}\text { Age at which mother } \\
\text { finished full time } \\
\text { education }\end{array}$} \\
\hline Up to 16 years & s 86 & 3.0 & 87 & $9 \cdot 0$ & 87 & $1 \cdot 0$ \\
\hline 17 to 18 years & 22 & $3 \cdot 0$ & 23 & $11 \cdot 0$ & 23 & $0 \cdot 0$ \\
\hline Over 18 years & 29 & $3 \cdot 0$ & 30 & $10 \cdot 0$ & 30 & $1 \cdot 0$ \\
\hline \multicolumn{7}{|l|}{$\begin{array}{l}\text { Mother's social } \\
\text { class } \$\end{array}$} \\
\hline Non-manual & 57 & $3 \cdot 0$ & 59 & $10 \cdot 0$ & 59 & 1.0 \\
\hline Manual & 76 & $3 \cdot 0$ & 77 & 9.0 & 77 & $1 \cdot 0$ \\
\hline
\end{tabular}

*On 3 weight charts the entries were not legible (eg smudged). +Number of mothers in each category of the variable.

\$The social class of 4 mothers was unclassified.

$\ddagger$ Significant difference $(\mathrm{P}<0 \cdot 025)$ using the Kruskal Wallis (non-parametric) test.

Social factors in the use of the booklet. A number of doctors and nurses, in their comments, had suggested that the booklet would be used by educated mothers in the higher socioeconomic groups and not by those who could actually benefit from it. An analysis of the number of weight points, record page entries, and developmental milestone entries as indicators of book use, by mothers' first language, education, and social class showed, however, that these comments were largely unfounded (Table 5). The only statistically significant difference was that mothers whose first language was English made more developmental milestone entries.

\section{Discussion}

This evaluation was limited in its scope as new services often take several years to become established. The importance of the evaluation was shown, however, by the results, where a number of problems and desired modifications to the booklet were highlighted early enough to be incorporated into a new edition of the booklet. A plastic envelope to protect the booklet has been recommended. A new cover design, based on that of another publication, ${ }^{1}$ reflects the monitoring of health and growth and includes space for the child's name. The space for the photograph has been removed and spaces added for other records such as the baby's hospital and NHS numbers. New simpler unisex weight charts extend over two pages and the axes, space, layout, legends, and instructions have been improved to facilitate the parental desire to plot charts. The centile lines have been made faint to reduce parental anxiety. Other sections have been modified slightly to improve the recording of information. The back cover now has a metric weight conversion chart. The previous immunisation card has been discontinued.

The benefits of the use of such a document, crossing the boundaries of disciplines and authorities, improving the relationship between parents and professionals, improving communication between professionals, and providing information to new authorities when parents move to other areas were all echoed in the comments on the booklet by general practitioners, health visitors, and clinical medical officers. Most professionals stressed, however, that these values were dependent on everyone using the booklet. Some of the reservations about the booklet expressed included the acceptance of yet another record to update, medicolegal problems, confidentiality of the information, disclosure of sensitive information, for example on nonaccidental injuries, and parental anxiety related to variations in weight. The potential savings in professional and secretarial time and postage for the communication of routine information should not be ignored and are commonplace with the use of maternity, diabetic, and hypertension cooperation cards.

There are other potential uses of such a booklet. A solution to the demand for the inclusion of health education, which has been tried quite successfully, is the production of a separate leaflet with notes on preventive services, child health clinics and immunisation, and developmental assessment schedules, of similar appearance and handed out at the same time as the child health booklet. A translated version in local ethnic languages is available. Delays in the communication of postnatal problems in hospital to community nurses could be overcome by entering information into the child health booklet on the wards, or sending it to the community nurses, via the mother on discharge from the ward, on a pre formatted sticky label to be stuck in the booklet.

There is further potential evolution of the record. Maternity cooperation cards have been used for several years in many health authorities. In one hospital antenatal clinic and in some joint hospital and community clinics in the West Lambeth Health District pregnant women carry the only record of antenatal health care and this feature of the service is currently being evaluated in this health district and in Oxford. These records could be combined with the child health record to produce a joint maternity and child health record booklet, kept at home by mothers. Our booklet was not designed to be the only health record; there is insufficient space 
in it to record details of signs and symptoms of illnesses and details of development assessment. The evaluation was thus not carried out in the context of this being the only child health record. A home based record which is the only health record may evolve but progress towards it is likely to be slow. In the current debate on the right of patients to examine their own medical records a number of arguments have been voiced about the potential problems with this, including medicolegal problems, confidentiality of third party information, interpretation of the information by patients, the recording of information on sensitive diagnoses, and the recording of subjective assessments of the patients by doctors. These arguments were reflected in some of the comments on the child health record by the health professionals, and are added as a note of caution by a working group of the British Medical Association, looking at the issues of patient access to medical records. ${ }^{6}$ In some countries in the world, where the costs of central record storage and retrieval facilities are prohibitive, there is a cultural acceptance by both patients and professionals of patient held records. Many doctors in England treating patients from overseas are used to these patients arriving with their own notes, radiographs, investigation reports, and open letters from their doctors containing details of diagnoses and prognoses.

We wish to thank Dr M Allsop, Dr G Clayden, Mr P Drury, Mrs M Green, Professor D Morrell, Mrs H Peston, and other members of the Child Health Record Steering Group, Mr R Morris for additional statistical help and the Department of Community Medicine, St Thomas's Hospital Medical School and the Special Trustees at St Thomas's for funding and supporting the research.

\section{References}

${ }^{1}$ Morley D, Woodland M. See how they grow. London: MacMillan Press, 1979.

2 World Health Organisation. A Growth chart for international use on maternity and child health care, guidelines for primary health care personnel. Geneva: WHO, 1978.

3 Carnet de Sante. Ministerie de la Sante, France.

${ }^{4}$ Drucquer M. Child health services in France-vive la difference. $\mathrm{Br}$ Med J 1983;286:1529-30.

5 Owen CM. Child health record booklet. Midwife, Health Visitor and Community Nurse 1980;16:156-62.

6 British Medical Association Council. Data protection: Council discusses interprofessional statement. Br Med J 1983;286:1592.

Correspondence to Dr A D Lakhani, Department of Community Medicine, St Thomas's Hospital Medical School, London SE1 7EH.

Received 23 July 1984 